\title{
Do procedimental à simulação: a partir de onde pensar os jogos digitais
}

\section{Rodrigo Campanella Gonçalves Barbosa e Regina Helena Alves da Silva}

\section{Resumo}

Partindo da compreensão do jogo como programa computacional e delimitando características que permitem compreendê-lo como um ambiente digital, este artigo busca compreender a relação entre as possibilidades do jogador em vídeo games, a construção das regras em um jogo digital e as teorias que tentam definir as propriedades desses jogos, mais próximas à narrativa ou à simulação. Também é discutida a forma de interação emergente ou progressiva, o papel das regras, do aprendizado e dos obstáculos dentro deses jogos.

\section{Palavras-chave}

Jogos digitais. Ludologia. Video games. Ambientes digitais. Simuladores

\section{Rodrigo Campanella Gonçalves Barbosa}

| rodrigo.campanella@gmail.com Mestrando no Programa de Pós-Gradução em Comunicação Social da Universidade Federal de Minas Gerais (UFMG)

\section{Regina Helena Alves da Silva}

I regina.helena@gmail

Pós-doutora em Arquitetura e Urbanismo pela UFBA (2009) e pósdoutora em Cidades e Culturas Urbanas pelo Centro de Estudos Sociais da Universidade de Coimbra. Atualmente é Professora Associada IV da Universidade Federal de Minas Gerais (UFMG) e atua nos programas de pós-graduação em História e em Comunicação Social.

\section{Simulação, imersão: a máquina em estado de jogo}

Na década de 1960, quando os computadores começavam a aprender a jogar, um programador da International Business Machines Corporation (IBM) percebeu que podia fazer com que eles cantassem. Naquele tempo em que as unidades de processamento de dados ocupavam andares inteiros de prédios, com 0 sistema de refrigeração permanentemente ligado para prolongar a vida útil das peças contra 0 superaquecimento, uma das formas de comunicação entre homens e computadores eram os cartões de papel perfurados, que assumiam o lugar de uma interface rudimentar. Inseridos em leitoras analógicas, os cartões indicavam através de seus pontos vazados quais operações deveriam ser efetuadas pela máquina, algo que posteriormente seria realizado com o uso de uma linguagem de programação através de um teclado.

A pesquisadora de interfaces digitais Janet Murray, que trabalhou como programadora na IBM, conta que as leitoras de cartões eram os componentes mais barulhentos das gigantescas 
máquinas de processamento de dados. Usando a mínima variação de sons mecânicos produzidos pela peça, um programador criou uma sequência de cartões que "[...] funcionava como o rolo de programação de uma pianola automática, fazendo a leitora de cartões emitir, com seus estampidos, uma versão reconhecível do Hino do Corpo de Fuzileiros: bam-bam-THUMP, bam-THUMP, bamTHUMP, THUMP-THUMP" (MURRAY, 2001, p. 18).

A sequência de códigos inserida nos cartões não tinha significado matemático ou computacional - sua função era reproduzir o ritmo do hino, largamente conhecido dentro da cultura norteamericana. A possibilidade de reproduzir músicas, ainda que rudimentares, fazendo uso de uma série de comandos predeterminada em um dispositivo externo, transporta para a mecânica do computador a mesma lógica que faz funcionar as pianolas automáticas - a conexão entre uma certa configuração material (no caso, as perfurações no papel) que assume a função de entrada de dados diante de uma máquina capaz de gerar certa resposta (ou transformação) a partir do recebimento de cada um desses dados. 0 piano automático funciona porque ao posicionamento das perfurações no rolo de papel corresponde a pressão sobre determinadas teclas, que permanecem emitindo som até que o espaço vazado no papel seja preenchido novamente.

A lógica que subjaz ao funcionamento dos jogos digitais é herdeira dessa mecânica primitiva de estímulos e respostas codificados, governando igualmente toda a relação entre os programas e 0 maquinário físico, as partes soft e hard de um sistema computacional. Jogos digitais são procedimentais, funcionando em uma lógica de máquinas de estado / state machines que condicionam como, a partir de um sistema de entrada (input) de dados, a máquina irá produzir certas respostas (ou alterações de estado) que tomam a forma de saídas (outpus) de dados. Ou seja, são programas de computador que guardam em si toda a configuração necessária para que se possa jogar.

Máquina de estados é aquela em que um estado inicial de funcionamento pode receber a influência de eventos ou informações externas, gerando uma nova saída (de dados), produzidos na forma de respostas regidas por um sistema de regras de "como proceder" diante dos dados recebidos, sistema que é estruturado na forma de "funções de transição de estado" (JUUL, 2005). Em resumo, ao duplo clique do mouse sobre o ícone do processador de texto estático na área de trabalho do computador (uma entrada de dados que altera um estado inicial da máquina), o computador ativa e coloca em funcionamento a cadeia de arquivos relacionados àquele programa (seguindo as regras de funcionamento de resposta, as "funções de transição") permitindo que ele seja aberto na tela do usuário e possa ser utilizado (a saída de dados relativa aos cliques iniciais).

Os jogos digitais percorrem essa mesma lógica de funcionamento dos programas computacionais 
- por isso são procedimentais. A cada ação do usuário no dispositivo utilizado como entrada de dados - joystick, teclado, mouse, sensor de movimento, tela sensível ao toque - 0 jogo digital apresenta uma resposta, que é também uma alteração em seu estado. Isso é o que permite que os programas de computador possam se configurar como jogos digitais: os jogadores podem executar suas ações em jogos embasados na certeza de que, excluída qualquer falha inesperada, o sistema de processamento de dados possui um sistema de regras capaz de responder aos seus comandos, contanto que tais comandos estejam no meio dos que são aceitos pelas regras daquele jogo específico.

Uma compreensão mais ampla de como funcionam os jogos está na caracterização de Janet Murray para os "ambientes digitais narrativos" ainda que, como veremos adiante, não existe necessidade e há mesmo limitações ao tentar compreender jogos como "narrativas". Porém, a definição de Murray não se sustenta sobre esse termo, ainda que em diversos momentos Murray veja nos ambientes digitais (e naquilo que denominamos jogos digitais) a possibilidade da consolidação de uma estrutura multinarrativa que abre novos horizontes literários. Para Murray (2001), os ambientes digitais são definidos como procedimentais, participativos, espaciais e enciclopédicos.

Ambientes procedimentais são aqueles estruturados como máquinas de estados com funções de transição possibilitando respostas a partir de entradas de dados, dentro de uma certa variedade de possibilidades que abrange simultaneamente os comandos que podem ser usados como entrada de dados e o número finito de funções para as quais o programa pode estabelecer respostas. No jogo de plataforma Super Mario World é possível ao personagem principal derrotar os animais que 0 ameaçam pulando sobre suas cabeças através do uso de um botão específico no joystick, mas não é possível usar o mesmo tipo de salto para, por exemplo, se apoiar sobre os arbustos que se estendem ao fundo como cenário fundo nas primeiras fases do jogo. Dentro da construção de Super Mario World, os arbustos fazem parte de um segundo plano estático com os quais não há interação prevista dentro de suas funções de transição.

\section{A participação nesses ambientes virtuais} configura-se no fato de que são as ações do usuário, usando um dispositivo de input, que orientam a resposta a ser disponibilizada pelo programa, alterando continuamente as condições iniciais do sistema e colocando em movimento a máquina de estados. Essa característica explicita o jogador/interator como participante do programa quando em funcionamento. Em Braid (Number None Inc., 2009), um jogo estruturado como um puzzle de plataforma, um dos comandos chave do jogo é a possibilidade de voltar no tempo ou de alterar 0 andamento temporal para conseguir vencer os desafios espaciais apresentados na sequência de fases do jogo. 
Figura 1: Braid: para resolver os desafios, é necessário manipular as ações e o tempo

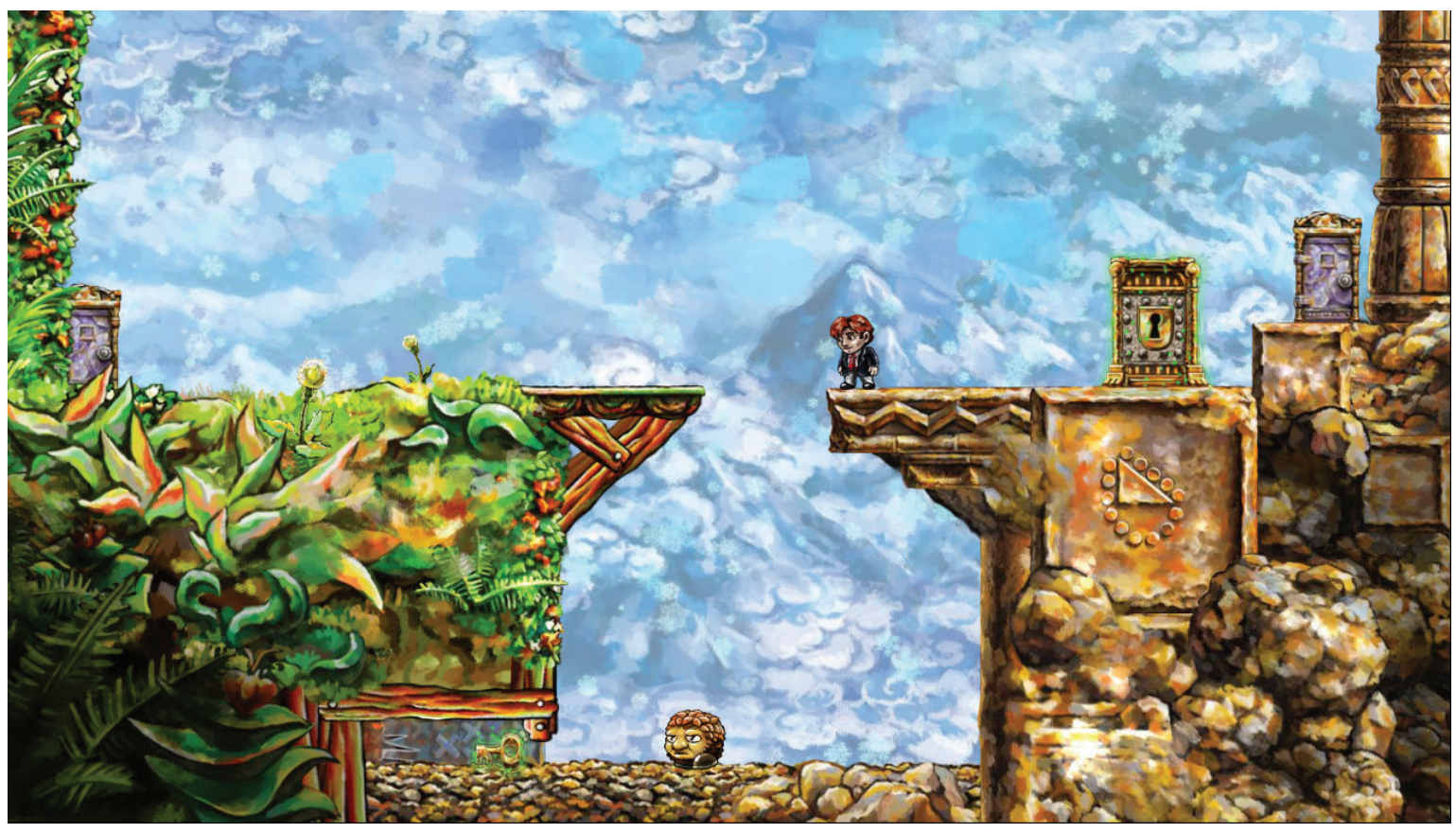

Fonte: Numbert None, Inc, divulgação

Na dinâmica do jogo Braid, apenas através da manipulação do tempo é possível reorganizar os elementos do jogo dispostos na forma de desafios (degraus de nuvens que evaporam, chaves guardadas em locais de onde não é possível retornar, alavancas que abrem passagens distantes por um tempo curto demais para alcançar) e 0 acerto desses elementos, muitas vezes conseguido apenas depois de dezenas de repetições, acontece com a alteração do próprio prosseguimento "linear" do jogo. Ao errar uma certa sequência de movimento ou precisar duplicar a ação do personagem - uma função possível em certas fases - é necessário pressionar um botão onde seus últimos movimentos são repetidos em ordem inversa, voltando no tempo dentro do ambiente de jogo até o ponto que o jogador considerar necessário para voltar "à velocidade normal" e resolver o desafio.
Ao criar um quebra-cabeças de movimentação onde o principal fator a ser manipulado é a passagem do tempo (e desse tempo em relação ao espaço), 0 criador do jogo, Jonathan Blow, investiga de modo inovador uma nova possibilidade da participação do jogador dentro desses ambientes digitais.

\section{A característica espacial definida por Murray} também está presente no mesmo Braid desde a introdução. Na primeira tela do jogo, a silhueta do personagem encontra-se parada na entrada de uma ponte - também vista apenas em sombra - que tem ao fundo a imagem estática de uma cidade que parece em processo de destruição. Passando pelas telas iniciais o personagem alcança uma casa vista em corte lateral, onde cada um dos cômodos aparece como um compartimento 
na tela. As portas internas de cada um dos cômodos representam a entrada das fases do jogo, que podem ser solucionadas em qualquer ordem. Cada fase é dividida em portas específicas que dão acesso a uma série de ambientes onde é necessário jogar com os elementos do espaço, com a passagem do tempo e com os adversários que atacam o personagem principal para chegar à saída da fase. Apenas após completar os cinco estágios do jogo aparecem todos os degraus necessários para se alcançar o sótão, onde está a porta para a "Fase 1", a última do jogo.

A qualidade enciclopédica expressa a capacidade desses ambientes em armazenarem uma enorme quantidade de informações, permitindo que 0 jogador/interator explore ambientes em grande escopo (percorrendo sem parar as quatro ilhas e centenas de fachadas de prédios que compõem 0 ambiente do jogo Grand Theft Auto IV) ou que ele se detenha em detalhes desses ambientes, como ler fragmentos de livros disponíveis no cenário ou dedicar certo tempo para ouvir a programação de rádios virtuais criadas exclusivamente para o mesmo Grand Theft Auto (GTA) IV, cada uma com programas, estilos musicais, debates temáticos e locutores específicos. 0 caráter enciclopédico constrói possibilidades de interação e de exploração do jogador com os ambientes e elementos do jogo em diversos níveis.

Em paralelo com as características intrínsecas dos jogos, as redes de jogadores que se formam através da internet, em torno de determinados jogos digitais, obrigam a compreender de modo mais estrito a afirmação inicial de Huizinga (1999) de que os jogos não têm consequências sociais e se encerram no fim de uma partida. Com a internet, grupos de discussões, fóruns de jogadores, modificações no cenário e nas ações do jogo (Mods) por grupos de jogadores e, mais recentemente, gravações de gameplays que podem ser vistas no Youtube e livestreams de jogos (onde o jogador exibe ao vivo uma partida, com a possibilidade de

Figura 2: A casa-menu de fases em Braid

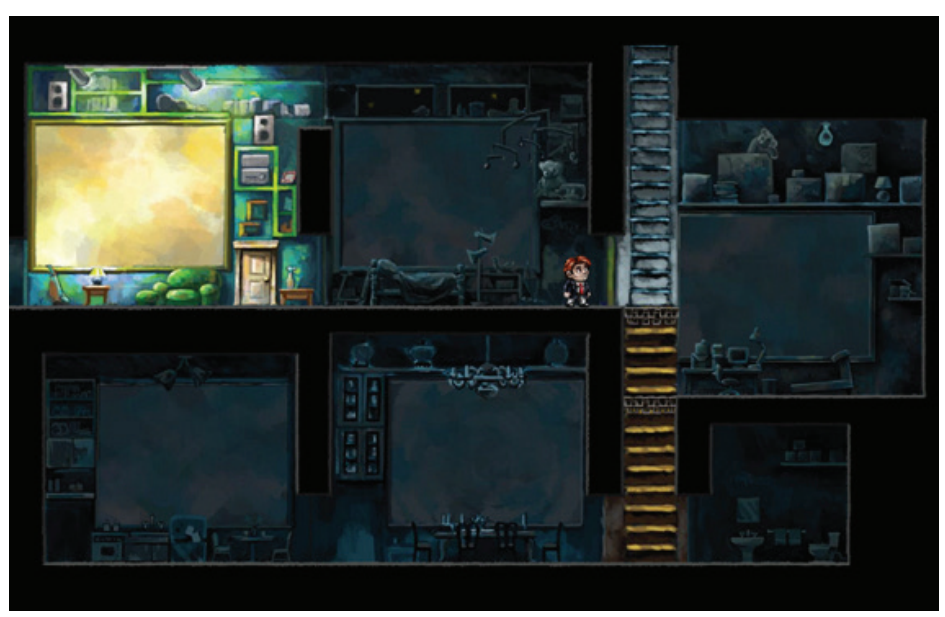

Fonte: Numbert None, Inc, divulgação 
um chat para interagir com o público) tornam-se cada vez mais comuns - e importantes para essas comunidades de jogadores.

Caillois (1990) já admitia que os torcedores que assistem um jogo performam uma espécie de mimesis, em que refletem em seu corpo as dificuldades dos atletas. Ainda que Huizinga estivesse preocupado em estabelecer a cisão entre o jogo e a vida cotidiana para não se exigir do jogo uma função "de ordenação social", preservando seu caráter de experimentação, o modo como ele colocou essa questão parece cada vez mais insuficiente.

Nos jogos digitais contemporâneos, os limites são enfraquecidos entre o que se joga, 0 que se aprende vendo os jogos dos outros e em como se estabelecem relações entre esses que exploram os jogos ou observam outros jogarem. Parece razoável pensar que esses jogos - procedimentais, participativos, espaciais e enciclopédicos (esse termo é chave para a exploração conjunta de vários jogadores) - expandem o limite daquilo que era "uma partida, com tempo e lugar determinado". Nos jogos digitais, a partida não se limita ao campo de jogo aberto diante da tela do jogador, mas é também a exploração conjunta com outros jogadores, a descoberta das possibilidades inexplícitas do jogo, as modificações possíveis no programa. Parece ser o próprio jogo que se expande, criando um ambiente de interação mais complexo do que a teoria inicial dos jogos dava conta de imaginar.

\section{Ludólogos, narratólogos e 0 grande embate que nunca esteve ali}

0 fato de a definição de Murray ser elaborada para dar conta de "ambientes digitais narrativos" serviu como princípio para descrever um lugar de tensão permanente - ainda hoje - no campo de estudo dos jogos digitais ou video games. A divergência existe na perspectiva de conceber os jogos digitais como um novo campo, multiforme, das narrativas mais tradicionais ou de compreender e estudar tais jogos como um novo formato cultural e artístico, em que a possibilidade de possuir certo viés narrativo não é o que lhe caracteriza e tal viés pode até mesmo ser compreendido como negativo em uma busca teórica por compreender o que seriam "os jogos" em si.

A divergência coloca em oposição dois grupos de pesquisadores. De um lado aqueles que seriam conhecidos como "ludólogos", defensores do estudo dos jogos como formato/produto cultural independente, criador de um novo paradigma de relação com 0 interator que tornaria impossível sua redução para a análise a partir de formatos tradicionais estabelecidos anteriormente. No canto oposto, os denominados "narratólogos", defensores do estudo dos jogos digitais como veículos de narrativas múltiplas, enredos multiformes a partir de um mesmo ponto de partida, levando a arte e a técnica narrativas até então estabelecidas a um novo patamar de possibilidades que não se esgotaria com apenas um percurso linear. 
Janet Murray, dentro da análise pretendida em Hamlet no Holodeck, estaria no front dos narratólogos, buscando as conexões possíveis entre a literatura, o cinema e as ficções de televisão junto dos ambientes amplos e passíveis de repetições e novos caminhos trazidos pelos jogos digitais.

A compreensão de Markku Eskelineen, que pode ser enquadrado entre os ludólogos, parte de uma direção oposta. Para ele, jogos digitais se caracterizam por contradizerem características associadas à narrativa ao serem manipuláveis, não apresentarem uma sequência linear de fatos e apresentarem os elementos que os compõem de modo não igualitário. Se em uma narrativa convencional todos os fatos e elementos dispostos apresentam igual valor para a completude da representação, do mesmo modo que não basta ler noventa por cento do livro para dar-se por satisfeito, nos jogos digitais não é necessário encontrar todas as combinações possíveis de eventos e ações que o jogo contém: "Jogar é visto aqui como prática configurativa, e a situação de jogo como uma combinação de fins, meios, regras, equipamentos e ação manipulativa" (ESKELINEN, 2001, tradução nossa). Há eventos e elementos (existents) que 0 jogador é obrigado a manipular a fim de prosseguir no jogo, mas estes não são os únicos componentes do jogo e nem há necessariamente uma forma única de lidar com eles.

Jesper Juul, que no início de sua carreira se apresentava como um ludólogo, observando a parte narrativa dos jogos apenas como uma forma de marketing para vender a mecânica das regras (JUUL, 1998), volta atrás nesse argumento em seu livro Half Real (2005), realizando um curto panorama, mais nuançado, sobre a discussão muitas vezes infrutífera acerca da importância da narrativa para se compreender o ethos dos jogos digitais, chegando à conclusão de que existe futuro no conceito de quests, que tenta se estabelecer como uma ponte entre as regras e a ficção do jogo, definindo os jogos como obras que contém uma sequência predefinida de eventos que devem ser atualizados ou encenados pelo jogador (JUUL, 2005).

Gonzalo Frasca, também compreendido como um "ludólogo," defende ainda na década de 1990 que os jogos não poderiam ser observados sob a mesma perspectiva das narrativas pois enquanto o jogar, ou ludus, é definido como um conjunto de possibilidades, a narrativa seria "um conjunto de ações encadeadas" (FRASCA, 1999, tradução nossa). Avançando a partir dessa proposição inicial, Frasca irá defender que a discussão entre "narratólogos e ludólogos" nunca se configurou como algo além de um pseudo-debate, onde aquela que seria a principal (e talvez única) defensora de uma compreensão "narrativa" dos jogos digitais, Janet Murray, nunca expressou uma proposição que seria contrária àquilo defendido pelos "ludólogos" - 0 estudo das características dos jogos a partir do ponto de vista de sua mecânica (FRASCA, 2003a).

A conclusão do pesquisador, após a retomada dos argumentos dos dois campos supostamente em 
embate, é que os chamados "ludólogos" nunca rejeitaram terminantemente a narrativa e nem buscam eliminar o elemento narrativo dos video games, restando que as acusações de radicalização associadas a este debate seriam, por todos os pontos de vista, infundadas (FRASCA, 2003a).

Em sua descrição do ambiente digital como "mundo narrativo", Murray novamente se aproxima de Frasca (de quem foi orientadora de mestrado), ao conceber um mundo que não conduz ou resolve uma única história:

[...] ao invés disso, compõe-se num sistema corrente de ações inter-relacionadas [...] Porque o computador é um meio procedimental, ele não se limita a descrever ou a observar padrões de comportamento, como os textos impressos e os filmes o fazem; ele incorpora e executa esses padrões (MURRAY, 2001, p. 175).

Para tentar encerrar a pretensa discussão, Murray (2005) irá argumentar que a suposta desavença entre os dois grupos de fato parece se dever a uma "ansiedade da influência", termo cunhado pelo crítico literário Harold Bloom para definir a necessidade que novos escritores (ou grupos) têm de se distanciar de suas primeiras influências, para estabelecer um campo próprio de produção (ou de estudos). Na visão de Murray, a impossibilidade de prosseguir no debate vem do fato de que os ditos "ludólogos" foram, na realidade, treinados na "narratologia" da qual buscam se separar. E reconhecendo que a abordagem puramente formalística e mecânica dos games trouxe muitos ganhos à área, alimentando o debate sobre 0 que são os jogos, as fronteiras entre jogos e outras formas culturais e as formas que os jogos assumem, não há debate a ser realizado nessa forma de embate direto, por falta de oponente real:

De fato, ninguém esteve interessado em construir 0 argumento de que não há diferenças entre jogos e histórias ou de que jogos são meros subgrupos de histórias. Aqueles interessados em jogos e histórias veem elementos de jogos em histórias e elementos de histórias em jogos: interpenetrando como categorias irmãs, nenhuma das quais absorvendo completamente a outra (MURRAY, 2005, tradução nossa).

\section{0 jogo como um outro lugar: simulação}

Frasca (2003a) irá sugerir sua própria definição para 0 estudo dos jogos digitais, estabelecida sobre o princípio da simulação. Sua proposta é que os video games não são baseados no princípio da representação, mas em uma estrutura semiótica definida como simulação, que guarda coincidência de elementos com a narrativa, mas possui funcionamento bastante diferente. Um fator que comprovaria isso é a dificuldade que a teoria tradicional e a semiótica ligadas à literatura teriam para lidar com os jogos, os ambientes virtuais e os textos multiformes "[...] porque estes trabalhos não são feitos somente de sequências de sinais, mas ao invés disso agem como máquinas ou geradores de sinais" (FRASCA, 2003b, p. 223, tradução nossa).

Ainda que observar um filme e uma partida de um jogo possa fazer supor materiais idênticos, 
Frasca defende que a simulação não pode ser compreendida através dos resultados que gera - voltando a um exemplo anterior, assistir no Youtube a uma partida de Braid previamente jogada por outro usuário não pode ser compreendido como a experiência do jogo propriamente, mas apenas como a visualização de uma das possibilidades de manipular os elementos disponíveis e realizar uma sequência de jogo. Enquanto autores narrativos (no cinema, na literatura) trabalham com apenas uma sequência de eventos - ainda que essa sequência não seja necessariamente linear internamente e diversas estruturas de tempo possam ser estabelecidas dentro do prosseguimento dos fatos - na experiência dos jogos a repetição para buscar novos modos de superar os desafios e interagir com os elementos virtuais não somente é possível como é necessária, pois o conhecimento interpretativo em simuladores depende de repetições (FRASCA, 2003b).

Frasca aponta que simuladores são laboratórios para experimentação, onde a ação do usuário não é apenas permitida, mas sim requerida, pois até mesmo o prazer dos simuladores encontra-se na possibilidade do interator de interromper e modificar as séries de ações. Essa caracterização fica ainda melhor definida na forma como Jesper Juul apresenta os conceitos de "árvore do jogo" (game tree) e "sessão de jogo" (gameplay). A árvore do jogo refere-se ao horizonte de possibilidades permitido pela máquina de estados do jogo, "[..] uma game tree ramificada de possibilidades momento após momento durante 0 ato de jogar um jogo. Jogar um jogo é interagir com a máquina de estados e explorar a árvore do jogo" (JUUL, 2005, p. 56, tradução nossa). Já a sessão de jogo (ou gameplay) é o modo como o jogador efetivamente se comporta enquanto tenta superar os desafios em um jogo, "[...] uma interação entre as regras e a tentativa do jogador de jogarum jogo da melhor forma possível" (JUUL, 2005, p. 56, tradução nossa).

Observar em um vídeo no Youtube a sequência linear de fatos gerada pelo usuário ao jogar Braid, Super Mario World, Manic Miner ${ }^{1}$ ou GTA é ter acesso apenas a uma das muitas sessões de jogo possíveis, a um dos gameplays possibilitados pela árvore do jogo. A soma virtualmente infindável das possibilidades de interação que um jogo oferece, definida pela árvore, é o que consolida seu caráter de simulação em contraponto aos diversos formatos narrativos em que a sequência é única: "[...] autores narrativos (ou "narrautores") possuem apenas um tiro em suas pistolas - uma sequência fixa de eventos" (FRASCA, 2003b, p 227, tradução nossa). 
A demanda de sucessivas sessões de jogo para explorar a árvore de possibilidades da máquina de estados e compreender como superar os desafios apresentados é o que leva Juul (2013) a visualizar os vídeo games como "a arte da falha" (the art of failure), onde a imposição de uma derrota é a ferramenta central, nos jogos digitais, para que 0 jogador encontre satisfação no aprendizado e na superação posterior, impulsionado pela sensação de perda e frustração. Jogos são estruturados sob a perspectiva dos desafios que apresentam, na explanação teórica de Juul, o que retoma necessidade de um objetivo (ainda que esse objetivo possa ser escolhido pelo jogador entre vários) e uma tensão, da incerteza da vitória, apontadas por Huizinga (1999) e Caillois (1990).

É preciso garantir aos jogadores que, ao menos temporariamente, irão falhar e só depois de exploração e aprendizado obterão satisfação (JUUL, 2013). Nesse ponto, Juul retoma Caillois (1990) em sua diferenciação entre paidia e ludus, onde a atratividade do último estaria na autoimposição de desafios artificialmente estabelecidos capazes de criarem dificuldades que seriam superadas apenas depois de treinamento, compreensão e aprendizado, sendo por isso considerado pelo antropólogo como uma instância "superior" à paidia no processo de evolução do homem.

Os desafios e obstáculos impostos pelos jogos são estruturados pelos mesmos elementos que indicam quais são as ações permitidas dentro do jogo: as regras. Como estruturadoras do jogo, as regras podem ser fáceis de aprender, para 0 jogador, mas usualmente irão estabelecer uma complexidade maior do que sua soma simples pode supor (JUUL, 2013). A partir de um pequeno conjunto de regras colocado em ação o horizonte de possibilidades abre-se para uma plêiade de estratégias que podem ser articuladas rumo a um objetivo (ou mais de um) estabelecido, algo multiplicado em jogos digitais que envolvem a competição entre vários jogadores. As regras não estabelecem apenas o jogo, mas definem sua complexidade. A proficiência de um jogador, a partir de um conjunto mínimo de regras como as do gamão ou do xadrez, demanda grande disponibilidade de tempo e esforço, com uma complexidade estratégica crescente.

No caso dos jogos digitais, Juul irá propor uma classificação que estabelece "jogos progressivos" ou "jogos emergentes" conforme as diferenças estabelecidas nas regras em relação aos modos de obter a vitória e vencer os obstáculos estabelecidos pelo jogo. Jogos com características emergentes são aqueles de poucas regras definidas que dão abertura a muitas combinações estratégicas, sendo fáceis de aprender, mas difíceis de dominar. Jogos progressivos são os que apresentam uma série de desafios sequenciais com regras únicas de resolução/superação que definem o modo como o jogo é encaminhado. $\mathrm{Na}$ estrutura progressiva, é dado forte controle ao designer sobre a condução do jogo, deixando-0 mais próximo das narrativas tradicionais na visão de Juul (2005, p. 73, tradução nossa): "[...] 
como o designer controla a sequência de eventos, é também aqui que nós encontramos jogos com ambições cinemáticas ou de storytelling".

As classificações oferecidas por Juul não são estáticas: é possível aos jogos serem compreendidos dentro de graus variados entre a progressão e a emergência, tendo como eixo sua característica principal entre as duas, resultando em classificações de jogos "emergentes com certo grau de progressão" ou "progressivos com certo grau de emergência" conforme estruturado pelo sistema de regras. A característica emergente dos jogos digitais indica que seus elementos são fortemente conectados - cada escolha ou ação influencia as escolhas posteriores e encontrase, até certo ponto, determinada pelas ações realizadas até aquele momento (JUUL, 2005).

Ao descrever as propriedades de agência do jogador em ambientes digitais - a possibilidade de que suas ações gerem resultados tangíveis dentro desses ambientes - Murray (2003) faz uma diferenciação de modos de funcionamento que antecipa as definições de Juul. A classificação da pesquisadora se divide entre ambientes digitais estruturados como um "labirinto solucionável" e como o "rizoma emaranhado". 0 primeiro seria como um quebra-cabeças (puzzle) baseado em um labirinto, onde é necessário descobrir, ativamente, as passagens sucessivas que levam 0 interator/ jogador adiante rumo a um sentido único de vitória. No modo como o Ulisses de Homero consegue enganar o ciclope e escapar da caverna, em uma sucessão de etapas progressivas e independentes, ela encontra "[...] uma série de passos lindamente orquestrados: um elegante algoritmo para derrotar gigantes" (MURRAY, 2003, p. 137). Nos jogos, é a série de fases ou ações que devem ser repetidas na sequência exata imaginada pelos designers do jogo, onde achar a ordem correta das peças desbloqueia o enigma ou desafio seguinte.

Já o rizoma emaranhado, mais próximo, mas não equivalente aos jogos emergentes, vai apresentar um "labirinto insolúvel" marcado pelas muitas possibilidades de vagar por um ambiente digital, através de caminhos que nunca se definem ou apontam para saída única, sempre abertos para a surpresa e cercados por uma ameaça constante que impele 0 jogador adiante. 0 fator reconfortante do rizoma emaranhado é que a falta de expectativa de uma resolução última também garante certa proteção contra 0 sentimento de perda, onde "[...[ a inexistência de limites na experiência do rizoma é crucial para 0 seu aspecto reconfortante. Nesse sentido, ela é um jogo tanto quanto o labirinto de aventuras" (MURRAY, 2003, p. 133). Se 0 caráter emergente observado no rizoma pode parecer equivocado para observar jogos clássicos - como o xadrez, o futebol, o gamão, os jogos de cartas - a aproximação entre as duas classificações será mais forte nos jogos digitais de ambiente aberto, onde 0 jogador pode se distanciar de um "objetivo final" indicado pelas regras e se reconstruir na forma de um vagar, de uma experimentação do ambiente digital. 
Figura 3: A possibilidade de explorar os ambientes em Grand Theft Auto IV

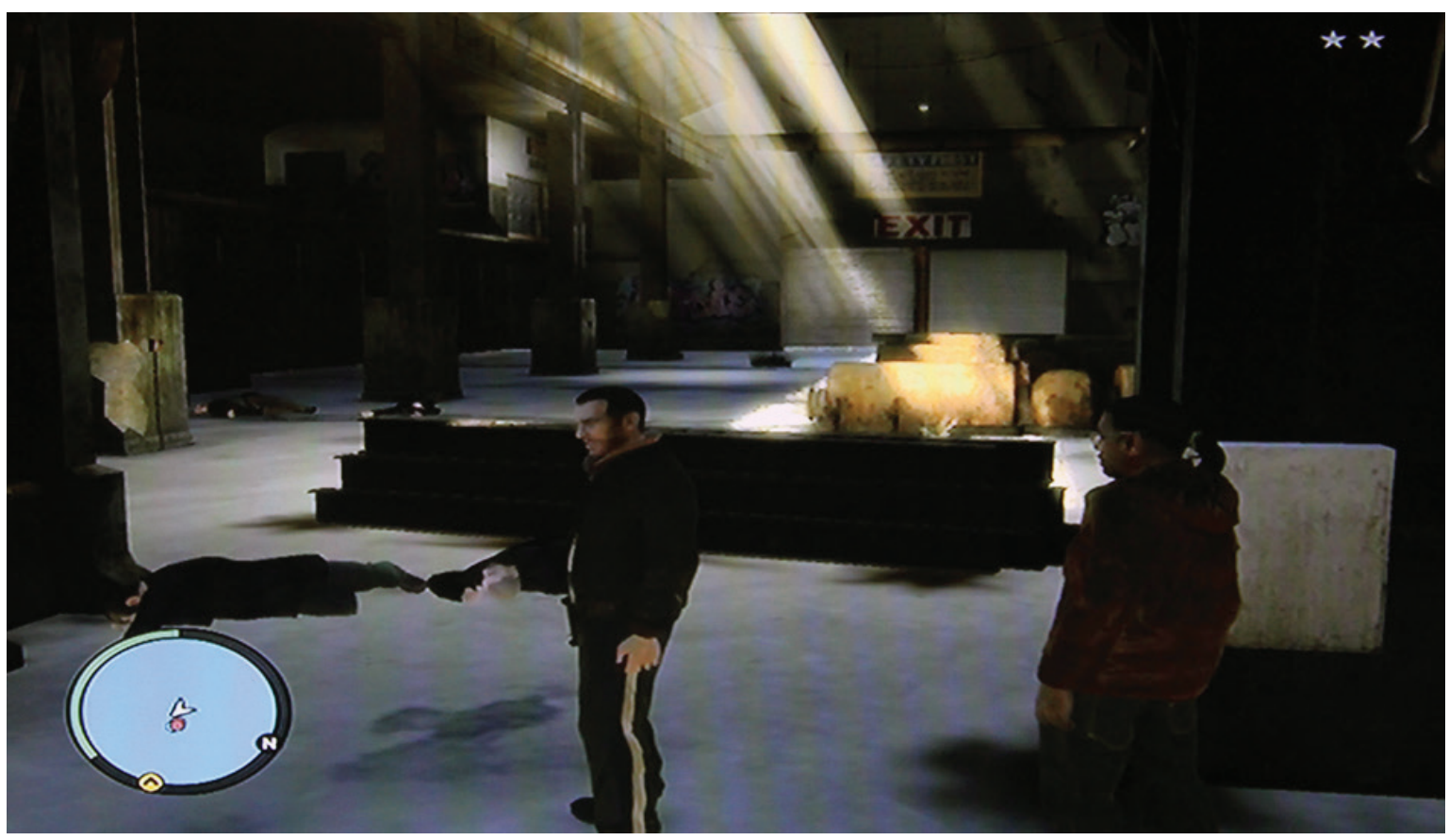

Fonte: Imagem de uma sessão de jogo dos autores do artigo.

Em jogos de ambiente aberto como Grand Theft Auto IV ou Bioshock, é possível compreender a forma como as ações permitidas ou demandadas ao jogador são construídas dentro destas duas formas, seguindo as formas arquetípicas de construção da agência em obras narrativas ou multinarrativas, conforme existe a liberdade para desvendar diversos caminhos de resolução e interação ou apenas a descrição contínua de uma solução única (um algoritmo) para a série de eventos apresentada. Nestes dois exemplos, é permitido ao jogador tanto seguir a série de tarefas demandadas pelas várias missões para chegar "ao fim" do jogo (e da narrativa que ele constrói) ou também é permitido, dentro de certos limites de interação do programa, explorar os ambientes e interagir com cenários ou personagens que não estão incluídos nessas tarefas. Ou seja, é possível seguir nesses jogos uma forma mais próxima ao "labirinto" ou ao "rizoma" definidos por Murray, de acordo com as opções do jogador dentro de cada sessão de jogo.

As classificações de progressivo ou emergente partem da estruturação por regras que configura os jogos, o que permite ao jogador aprender a jogar dentro de uma estrutura procedimental - com base em regras bem definidas e sabendo que, dentro de um mesmo conjunto de regras, a resposta do jogo às suas ações será aquela estabelecida desde o princípio, a não ser no caso do jogo explicitamente informar sobre qualquer mudança em seu sistema procedimental de ação-e-resposta. 0 aprendizado interno ao 
jogo e a própria confiança em "aprender como jogar" para superar os obstáculos do jogo digital existem também no fato de que essas mesmas regras (algorítmicas) definem o que pode ou não ser realizado dentro de um jogo: as "ações significativas" disponíveis ao jogador.

Em sua busca por uma definição do que seriam as regras de um jogo, Juul concorda com Katie Salen e Eric Zimmerman (2003) de que elas são em parte "conjuntos de instruções" que limitam as ações do jogador. Mas ao limitar certas ações, as regras também definem quais são as ações possuem sentido dentro do jogo - aquelas que constituem uma obrigação e um certo fazer que se reflete diretamente na dinâmica do jogo:

[...] as regras de um jogo também definem ações potenciais, ações que são significativas dentro do jogo porém sem sentido fora dele. São as regras do xadrez que permitem ao jogador fazer um xeque-mate - sem as regras, não há xeque-mate, somente movimentação de peças sem sentido ao longo de um tabuleiro (JUUL, 2005, p. 58, tradução nossa).

0 jogo de basquete apresenta outro exemplo para a definição negativa (limitações) e positiva (modos de fazer) das regras. Somente conhecendo as regras que configuram o jogo de basquete é possível entender e agir nesse sentido: alternar a bola entre a mão e 0 chão enquanto se desloca, atingir o espaço delimitado como "a área adversária" e passar a bola pelo aro metálico com rede de poliéster (ou "cesta") para contabilizar "pontos", que são a medida utilizada para dizer da superioridade de um time sobre o outro durante uma partida. Apenas as regras também explicam que arremessos de fora da área adversária (ou "garrafão") valem três pontos e que "faltas" são penalizadas com a perda da posse de bola ou com "tiros livres", arremessos diretos feitos pelo jogador no garrafão adversário.

As várias aspas na definição anterior esclarecem como são as regras que definem quais tipos de ações, de modo positivo e negativo, terão significado dentro da partida. A definição passageira de Juul para as regras como definidoras de "ações potenciais" parece insuficiente para lidar com essa duplicidade de significação que elas possuem na estrutura do jogo. Por isso, fazemos a opção em focar no termo meaningful e compreender, dentro deste artigo, as regras como definidoras das "ações significativas" que têm a capacidade de gerar um estado de jogo e possibilitam aos jogadores saber que "estão jogando" e como agir ali dentro para alcançar determinados objetivos que nem sempre são apenas o "grande objetivo" aparente - pois sempre pode haver o jogador que, em uma partida de basquete, deseje apenas quebrar seu próprio recorde de pontos.

Nos jogos digitais, as ações significativas estão definidas na programação do jogo - seja nas ações disponíveis no dispositivo de interação/entrada de dados (os botões do mouse, do teclado, do joystick, da tela sensível a toque) e no modo como essas ações são capazes de agir sobre os outros elementos do ambiente de jogo. 
Figura 4: Em Streets of Rage 2 não é possivel entrar nas fachadas desenhadas ao fundo

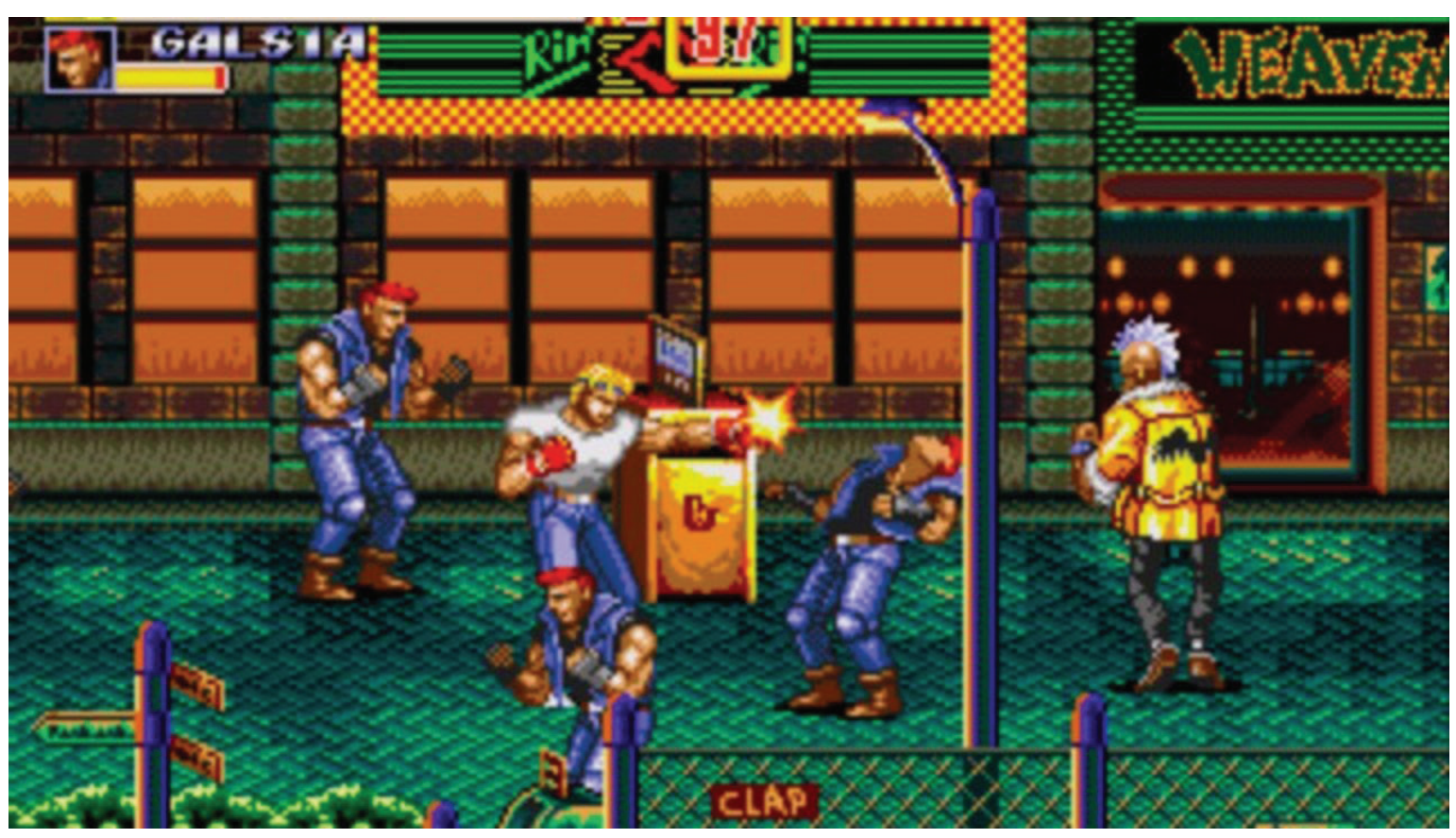

Fonte: Sega Corporation, divulgação

Em dois exemplos rápidos de como um único comando do joystick pode dar vazão a uma variedade de ações, a possibilidade de abrir portas em um jogo que simula um grande território urbano permite que o jogador possa interagir com diversos ambientes internos (ou externos), criando explorações potencialmente únicas a cada sessão de jogo (ou a cada "partida"). E a possibilidade de pular, nesse mesmo jogo imaginado, permite que o jogador salte sobre objetos ou pequenos obstáculos na rua (muretas na fachada de casas, por exemplo) ou que ele consiga alcançar, através do salto, janelas e outras entradas para locais que parecem inacessíveis ou que ele possa mesmo abrir portas de edifícios, explorar seu interior até 0 último andar e retornar ao chão em um puro movimento de vertigem
- às vezes subindo até 0 topo de um prédio e saltando lá do alto, muitas vezes perdendo apenas uma "vida", parte da sua "energia" ou o dinheiro necessário para um "tratamento médico" revitalizador, no caso da série de jogos Grand Theft Auto, onde tal movimento é possível. Sem o comando de abrir portas ou de pular existentes como parte do software, seria impossível realizar essas ações, mesmo que portas estivessem desenhadas (como no jogo Streets of Rage 2, por exemplo) ou obstáculos no caminho do personagem controlado pelo jogador.

Permitir a passagem para esses ambientes anteriores ou o salto sobre obstáculos adiante é uma escolha, uma construção dos realizadores do jogo, que pode ser mais ou 
menos significativa conforme contribua para se alcançar ou criar um objetivo. Não existem comandos gratuitos criados em jogos - cada ação possível é uma construção anteriormente pensada e executada. Mas isso também não quer dizer que tudo que o jogador poderá realizar com aquelas ações também foi programado - a rede de interações é muito mais complexa e ampla do que a definição das ações individuais.

A escolha do salto do alto do prédio como saída, no último exemplo dado, não é mórbida de modo gratuito - ela existe aqui para relembrar que 0 jogo, especialmente o jogo digital, não é a vida concreta ou uma experiência similar a esta. 0 jogo, como Huizinga (1999) e Caillois (1990) definem, encontra-se à parte da vida corrente, dentro de um estado próprio de regras, mas sem perder de vista a existência dessa vida que 0 rodeia.

\section{Referências}

BIOSHOCK. Ken Levine. Irrational Games. 2K Games, 2007. Dvd de Microsoft Xbox 360.

BRAID. Jonathan Blow. Number None, Inc., 2009. Microsoft Windows.

CAILLOIS, Roger. 0s jogos e os homens: a máscara e a vertigem. Lisboa: Cotovia, 1990.

ESKELINEN, Markku. The Gaming Situation. Game Studies (online), v. 1, n. 1, 2001. Disponível em: < http://www.gamestudies.org/0101/eskelinen/>. Acesso em: 06 mar. 2014.

FRASCA, Gonzalo. Ludology meets narratology. Parnasso, 3: Helsinki, 1999. Disponível em < http:// www.ludology.org/articles/ludology.htm > . Acesso em:
06 mar. 2014

FRASCA, Gonzalo. Ludologists Love Stories, Too: Notes from a Debate that Never Took Place. In: COPIER, Marinka; RAESSENS, Joost (Ed.). Level Up: Digital Games Research Conference Proceedings. Utrecht: DiGRA and University of Utrecht, 2003a. Simulation vs. Narrative. In: WOLF, Mark J. P.; PERRON, Bernard. The Video Game Theory Reader. New York: Routledgepp, 2003b, p.221-235

FRIEDMAN, Ted. Civilization and its discontents. In: SMITH, Greg M. On a Silver Platter: Cd-Roms and the Promises of a New Technology. New York: New York University Press, 1999, p. 132-150.

GRAND THEFT AUTO IV. Rockstar North. Rockstar Games, 2008, Dvd de Microsoft Xbox 360.

HUIZINGA, Johan. Homo Ludens: o jogo como elemento da cultura. São Paulo: Perspectiva, 1999.

JUUL, Jesper. A Clash between Game and Narrative. [S.I.]: Noruega, 1998. Disponível em < http://www. jesperjuul.net/text/clash_between_game_and_ narrative.html>. Acesso em: 6 fev. 2014.

Half-real: Video Games between Real Rules and Fictional Worlds. Cambridge: MIT Press 2005.

. A Casual Revolution: Reinventing Video Games and Their Players. Cambridge: MIT Press, 2009.

. The art of Failure: An essay on the pain of playing video games. Cambridge: MIT Press, 2013.

MURRAY, Janet H. Hamlet no Holodeck: 0 futuro da narrativa no ciberespaço. São Paulo: Editora UNESP/ ITAÚ Cultural, 2001.

The Last Word on Ludology. v Narratology. In: Proceedings of DiGRA 2005 Conference: Changing Views - Worlds in Play, 2005. Disponível em < http:// inventingthemedium.com/2013/06/28/the-last-word-onludology-v-narratology-2005/ $\geq$. Acesso em: 5 fev, 2014. RYAN, Marie-Laure. Immersion vs. Interactivity: Virtual 
Reality and Literary Theory. In: Substance, n. 89 (

volume 28, número 2). Madison: University of Wisconsin

Press, 1999, p. 110-137

SALEN, Kate; ZIMMERMAN, Eric. Rules of play: game

design fundamentals. Cambridge: The MIT Press, 2003.

STREETS OF RAGE 2. Sega, Sega 1993. Cartucho, Sega Genesis.

SUPER MARIO WORLD. Takashi Tezuka. Nintendo

EAD. Nintendo, 1990. Cartucho, Super Nintendo. 
From procedurality to simulation: where to begin thinking on the digital games

\section{Abstract}

Starting from the understanding of the game as software and defining the characteristics that allow us to recognize it as a digital environment, this article seeks to understand the relationship between the possibilities given to players in video games, the creation of rules in a digital game and theories that attempt to define the properties of these games, closer to the narrative or simulation. It is also discussed the form of emergent or progressive gameplay and the role of rules, learning and obstacles within these games.

\section{Keywords}

Digital games. Ludology. Video games. Digital environments. Simulators

\section{Desde lo procedimental a la simulación: desde donde pensar juegos digitales}

\section{Resumen}

A partir de la comprensión del juego como software y la definición de características que permiten entenderlo como un entorno digital, este artículo trata de comprender la relación entre las posibilidades del jugador de videojuegos, la construcción de unas reglas en juegos digitales y teorías que tratan de definir las propiedades de estos juegos, más cerca de la narrativa o la simulación. También se discutió la forma de interacción emergente o progresiva, el papel de las normas, el aprendizaje y los obstáculos en estos juegos.

\section{Palabras clave}

Los juegos digitales. Ludología. Videojuegos. Los entornos digitales. Simuladores 


\section{Expediente}

A revista E-Compós é a publicação científica em formato eletrônico da Associação Nacional dos Programas de Pós-Graduação em Comunicação (Compós). Lançada em 2004, tem como principal finalidade difundir a produção acadêmica de pesquisadores da área de Comunicação, inseridos em instituições do Brasil e do exterior.

\section{E-COMPÓS I www.e-compos.org.br I E-ISSN 1808-2599}

Revista da Associação Nacional dos Programas

de Pós-Graduação em Comunicacão.

Brasília, v.17, n.1, jan./abri. 2014.

A identificação das edições, a partir de 2008

passa a ser volume anual com três números.

\section{CONSELHO EDITORIAL}

Afonso Albuquerque, Universidade Federal Fluminense, Brasil Alberto Carlos Augusto Klein, Universidade Estadual de Londrina, Brasil Alex Fernando Teixeira Primo, Universidade Federal do Rio Grande do Sul, Brasil Ana Carolina Damboriarena Escosteguy, Pontifícia Universidade Católica do Rio Grande do Sul, Brasi

Ana Gruszynski, Universidade Federal do Rio Grande do Sul, Brasil Ana Silvia Lopes Davi Médola, Universidade Estadual Paulista, Brasil André Luiz Martins Lemos, Universidade Federal da Bahia, Brasi Ângela Freire Prysthon, Universidade Federal de Pernambuco, Brasil Antônio Fausto Neto, Universidade do Vale do Rio dos Sinos, Brasil Antonio Carlos Hohlfeldt, Pontifícia Universidade Católica do Rio Grande do Sul, Brasil Antonio Roberto Chiachiri Filho, Faculdade Cásper Líbero, Brasi Arlindo Ribeiro Machado, Universidade de São Paulo, Brasil Arthur Autran Franco de Sá Neto, Universidade Federal de São Carlos, Brasi Benjamim Picado, Universidade Federal Fluminense, Brasil César Geraldo Guimarães, Universidade Federal de Minas Gerais, Brasil Cristiane Freitas Gutfreind, Pontifícia Universidade Católica do Rio Grande do Sul, Brasil Denilson Lopes, Universidade Federal do Rio de Janeiro, Brasil Denize Correa Araujo, Universidade Tuiuti do Paraná, Brasi Edilson Cazeloto, Universidade Paulista , Brasil

Eduardo Vicente, Universidade de São Paulo, Brasil Eneus Trindade, Universidade de São Paulo, Brasil Erick Felinto de Oliveira, Universidade do Estado do Rio de Janeiro, Brasi Gelson Santana, Universidade Anhembi/Morumbi, Brasi Gilson Vieira Monteiro, Universidade Federal do Amazonas, Brasil Gislene da Silva, Universidade Federal de Santa Catarina, Brasil Guillermo Orozco Gómez, Universidad de Guadalajara Gustavo Daudt Fischer, Universidade do Vale do Rio dos Sinos, Brasil Hector Ospina, Universidad de Manizales, Colômbia Herom Vargas, Universidade Municipal de São Caetano do Sul, Brasil Ieda Tucherman, Universidade Federal do Rio de Janeiro, Brasil Inês Vitorino, Universidade Federal do Ceará, Brasil Janice Caiafa, Universidade Federal do Rio de Janeiro, Brasil Jay David Bolter, Georgia Institute of Technology Jeder Silveira Janotti Junior, Universidade Federal de Pernambuco, Brasi João Freire Filho, Universidade Federal do Rio de Janeiro, Brasil Florence Dravet, Universidade Católica de Brasília, Brasil John DH Downing, University of Texas at Austin, Estados Unidos

José Afonso da Silva Junior, Universidade Federal de Pernambuco, Brasil José Carlos Rodrigues, Pontifícia Universidade Católica do Rio de Janeiro, Brasil José Luiz Aidar Prado, Pontifícia Universidade Católica de São Paulo, Brasil José Luiz Warren Jardim Gomes Braga, Universidade do Vale do Rio dos Sinos, Brasil Juremir Machado da Silva, Pontifícia Universidade Católica do Rio Grande do Sul, Brasil Laan Mendes Barros, Universidade Metodista de São Paulo, Brasil Lance Strate, Fordham University, USA, Estados Unidos Lorraine Leu, University of Bristol, Grã-Bretanha Lucia Leão, Pontifícia Universidade Católica de São Paulo, Brasil Luciana Panke, Universidade Federal do Paraná, Brasil Luiz Claudio Martino, Universidade de Brasília, Brasil Malena Segura Contrera, Universidade Paulista, Brasil Márcio de Vasconcellos Serelle, Pontifícia Universidade Católica de Minas Gerais, Brasil Maria Aparecida Baccega, Universidade de São Paulo e Escola Superior de Propaganda e Marketing, Brasil Maria das Graças Pinto Coelho, Universidade Federal do Rio Grande do Norte, Brasil Maria Immacolata Vassallo de Lopes, Universidade de São Paulo, Brasil Maria Luiza Martins de Mendonça, Universidade Federal de Goiás, Brasil Mauro de Souza Ventura, Universidade Estadual Paulista, Brasil Mauro Pereira Porto, Tulane University, Estados Unidos Nilda Aparecida Jacks, Universidade Federal do Rio Grande do Sul, Brasil Paulo Roberto Gibaldi Vaz, Universidade Federal do Rio de Janeiro, Brasil Potiguara Mendes Silveira Jr, Universidade Federal de Juiz de Fora, Brasil Renato Cordeiro Gomes, Pontifícia Universidade Católica do Rio de Janeiro, Brasil Robert K Logan, University of Toronto, Canadá

Ronaldo George Helal, Universidade do Estado do Rio de Janeiro, Brasil Rosana de Lima Soares, Universidade de São Paulo, Brasi Rose Melo Rocha, Escola Superior de Propaganda e Marketing, Brasil Rossana Reguillo, Instituto de Estudos Superiores do Ocidente, Mexico Rousiley Celi Moreira Maia, Universidade Federal de Minas Gerais, Brasi Sebastião Carlos de Morais Squirra, Universidade Metodista de São Paulo, Brasil Sebastião Guilherme Albano da Costa, Universidade Federal do Rio Grande do Norte, Brasil

Simone Maria Andrade Pereira de Sá, Universidade Federal Fluminense, Brasi Tiago Quiroga Fausto Neto, Universidade de Brasilia, Brasil Suzete Venturelli, Universidade de Brasília, Brasil Valerio Fuenzalida Fernández, Puc-Chile, Chile Veneza Mayora Ronsini, Universidade Federal de Santa Maria, Brasil Vera Regina Veiga França, Universidade Federal de Minas Gerais, Brasil

\section{COMISSÃO EDITORIAL}

Cristiane Freitas Gutfreind I Pontifícia Universidade Católica do Rio Grande do Sul, Brasil Irene Machado I Universidade de São Paulo, Brasil

Jorge Cardoso Filho I Universidade Federal do Reconcavo da Bahia, Brasil / Universidade Federal da Bahia, Brasil

CONSULTORES AD HOC

Adriana Amaral, Universidade do Vale do Rio dos Sinos, Brasil

Alexandre Rocha da Silva, Universidade Federal do Rio Grande do Sul, Brasi Arthur Ituassu, Pontifícia Universidade Católica do Rio de Janeiro, Brasil Bruno Souza Leal, Universidade Federal de Minas Gerais, Brasil Elizabeth Bastos Duarte, Universidade Federal de Santa Maria, Brasil Francisco Paulo Jamil Marques, Universidade Federal do Ceará, Brasil Maurício Lissovsky, Universidade Federal do Rio de Janeiro, Brasil Suzana Kilpp, Universidade do Vale do Rio dos Sinos, Brasil Vander Casaqui, Escola Superior de Propaganda e Marketing, Brasil

EDIÇÃO DE TEXTO E RESUMOS I Susane Barros SECRETÁRIA EXECUTIVA I Helena Stigger EDITORAÇÃo ELETRÔNICA I Roka Estúdio
COMPÓS I www.compos.org.br

Associação Nacional dos Programas de Pós-Graduação em Comunicação

Presidente

Eduardo Morettin

Universidade de São Paulo, Brasil

eduardomorettin@usp.br

Vice-presidente

Inês Vitorino

Universidade Federal do Ceará, Brasil

ines@ufc.br

Secretária-Geral

Gislene da Silva

Universidade Federal de Santa Catarina, Brasil

gislenedasilva@gmail.com 